\title{
KINDERSPIELE AUS KULTURELLER UND LINGUISTISCHER SICHT
}

\section{ZUSAMMENFASSUNG}

Ich möchte mit dieser Arbeit ein Einblick in das Phänomen "Spiel" verschaffen und seine Möglichkeit in der Kultur und in der linguistischen Interaktion (Kommunikation) aufzeigen. Ausgangspunkte sind die Beziehungen zwischen Spiel und Kultur, Definitionen, Theorien und Merkmale über spiele. Auf der Grundlage theoretischer Ansätze werden im Folgenden auf die spiele der türkischen schüler auf dem Schulhof eingegangen. Für den Korpus wurden die spiele der Kinder auf Kamera aufgenommen. Anschließend wurden die spiele auf dem Schulhof aus motorischer- kognitiver-, sozialer-, psychischer-, emotionalerund sprachlicher Sicht beurteilt. Zum Schluss wurde die sprachliche Weltansicht der türkischen schüler dargestellt und einige kritische Überlegungen zu diesem Konzept angeführt.

Schlüsselwörter: Kinderspiele, Spiele aus Kultureller Sicht, Spiele aus Pädagogischer Sicht, Spiele aus Linguistischer Sicht, Weltansicht der Türkischen Kinder

\section{KÜLTÜREL VE DİLBİLIMSEL AÇIDAN ÇOCUK OYUNLARI}

\section{ÖzET}

Bu Çalışmada "oyun" olgusunun genel, kültürel ve dilbilimsel açıdan ne olduğu ve iletişimdeki yeri anlatılmaktadır. Çıkış noktasını ise oyunun kültür ile bağlantısı, tanımı, özellikleri ve ilgili teoriler oluşturmaktadır. Teorik bilgilerden sonra Türk öğrencilerin okul bahçesinde oynadıkları oyunlara değinilmektedir. Bütünce oluşturulurken çocukların teneffüste oynadıkları oyunlar kameraya çekilmiştir. Daha sonra oyunlar psikomotor, bilişsel, sosyal, ruhsal, duygusal ve dilsel açıdan değerlendirilmiştir. Sonuç bölümünde ise öğrencilerin dilsel dünya görüşlerine değinilerek bu konu ile ilgili birkaç eleştirel düşünce ileri sürülmüştür.

Anahtar Kelimeler: Çocuk Oyunları, Kültürel Açıdan Oyunlar, Pedagojik Açıdan Oyunlar, Dilbilimsel Açıdan Oyunlar, Türk Çocuklarının Dünya Görüşü 


\section{EINLEITUNG (GÍİŞ)}

Wer hat schon als ein Kind nicht gespielt? Jeder Erwachsene, aus welcher Kultur er auch stammt kann sich an die spiele, die er in seiner Kindheit gespielt hat bestimmt erinnern. Aber doch noch ist das Bereich "Spiel" und "Kindheit" uns Erwachsenen sehr fremd. StöcklinMeyer (2010:7) schreibt über das "spiel", was auch meist von den Erwachsenen nicht ernst genommen wird, folgendes: "Das spiel ist die Lebensform des Kindes und gleichzeitig die Sprache seines Herzens." Aus dieser Zeile sieht man, wie wichtig das spiel für das kind ist, und welche Funktion es in seinem Leben hat. Dem Kinderspiel sollte genügend Beobachtung von den Eltern, Erwachsenen und von den Forschern entgegengebracht werden. Wie es zum Schluss der Arbeit auch zu ersehen ist, ist das Bereich Kinderspiel auch für Linguisten forschungswert.

Im Spiel erleben alle Kinder auf der Welt egal welcher Nation sie angehören Abenteuer, Glück, Unglück, Bewegungsfreude, Ausdauer, Sprache und Phantasie. Dabei trainieren sie auch alle Muskeln von Kopf bis Fuß. Deswegen sind im spiel kulturspezifische und auch universale Elemente zugleich vorhanden. Pehlivan (2012:5) fasst die Gedanken von Doğanay (1988), Erden (2001) und Hatcher, Papae, Nicosia (1988) mit einem Satz folgendermaßen zusammen: "Obwohl die Formen, Eigenschaften und Sachen des spiels in jeder Zeitalter und in jeder Kultur verschieden waren, ist das Vorhanden sein des Spiels und Spielsachen wo es Kinder auf der Welt gibt eine Allgemeine Regel. Deswegen sind im Spiel kulturelle und auch universale Elemente gleichzeitig vorhanden." Nach Yücel-Gündoğdu (2012:1)wiederspiegelt das spiel die kulturellen Eigenschaften einer Gesellschaft und ist deswegen sehr wichtig. Durch das Spiel werden Sitten, Normen, Lebensstiele, Musik, Glauben u. ä. gesellschaftliche Eigenschaften den nächsten Generationen übertragen. Stöcklin- Meyer (2010:11) meint, das die Kinder im spiel Werte durch Beobachten, Nachahmen und eigenes Tun erwerben. Ein paar grundlegende Werte, die Kinder unbewusst im Kinderspiel erfahren können, sind nach Meyer Z.B.:

- Unterscheiden zwischen "mein" und "dein"

- Wahrheit und Lüge erkennen.

- Streit und Versöhnung verstehen und leben.

- Spielregeln einhalten oder neue aushandeln.

- Klar und eindeutig ausdrücken können, was man will und was nicht.

- Gefühle erkennen, leben, in Sprache fassen.

- Mit Anstand gewinnen oder verlieren.

- Sich in einem gemeinsam abgesteckten Rahmen einfügen und Regeln einhalten.

- Die "goldene Regel" befolgen: "Was du nicht willst, das man dir tut, das tu auch keinem anderen!" usw.

Zusammenfassend kann über die spiele der Kinder folgendes gesagt werden: Durch das Spiel reflektieren die Kinder ihre Innenwelt nach außen. Ihre Individualität und Gemeinschaftlichkeit werden im spiel gefördert. Das Spiel ist von der einmaligen Persönlichkeit des Kindes und von der Gesellschaft, von der Familie, von ihren Traditionen und Normen geprägt.

\section{DIE BEDEUTUNG DER FORSCHUNG (ÇALIŞMANIN ÖNEMİ)}

In den folgenden Zeilen werden kurz die Vorteile der Kinderspiele aufgezählt, um die Bedeutung der Forschung aufzuzeigen. Die Vorteile der Kinderspiele können folgendermaßen zusammengefasst werden. 
- Das Spiel ist eine Gelegenheit, in der sich die Kinder aktiv und intensiv mit sich selbst und ihrer Umwelt auseinander setzen. Das Spiel bietet den Kindern ideale Voraussetzungen für erfolgreiche Lernprozesse in allen Bereichen der kindlichen Entwicklung.

- Die Identität und die Persönlichkeit des Kindes werden im Spiel weiterentwickelt. Über eigene Stärken, Fähigkeiten und Grenzen werden Wissen erworben. Soziale und sprachliche Kompetenzen helfen ihnen dabei, zwischenmenschliche Beziehungen zu gestalten. Die Konflikte, die im spiel auftreten, können durch unterschiedliche Lösungsstrategien erprobt werden.

- Viele Fähigkeiten und Fertigkeiten, die für eine erfolgreiche Lebensgestaltung bedeutend sind, kommen aus intensiven Spielerfahrungen. Das aktive Tun im spiel lehrt den Kindern die Welt, in der sie leben und erweitert ihr persönliches Weltwissen Stück für Stück (Vgl. Özal Göncü 2012). Es ist z.B. das Wissen über Gegenstände oder Materialien, ihre Funktionsweise und das Erlernen neuer Begriffe. Die Alltagskompetenz dass als die Fähigkeit, alltägliche Herausforderungen zu verstehen und zu bewältigen zu verstehen ist wird im spiel gestärkt. Im Rollenspiel bevorzugen Kinder Themen, die mit ihren alltäglichen Erlebnissen zu tun haben, wie Einkaufen, Familienbeziehungen, Arztbesuche usw.

- Elementare Voraussetzungen wie etwa Konzentrationsfähigkeit, Kreativität und Selbstständigkeit die für die Bildungslaufbahn der Kinder wichtig sind, werden beim spielen erworben. Beim Kaufladenspielen sind mathematische Fähigkeiten und beim Bauen oder Konstruieren Abstraktionsvermögen und logisches Denken gefordert. Regelspiele, die im Volksschulalter erworben werden, verlangen ein hohes $M a ß$ an Anstrengungsbereitschaft und Frustrationstoleranz.

Kurz gesagt werden beim spielen motorische-, kognitive-, motivationale-, soziale-, psychische-, emotionale- und sprachliche Bereiche gefördert.

Kurzgesagt versucht das Kind im zweckfreien Spielen, seine Lebenswelt $\mathrm{zu}$ begreifen und $\mathrm{zu}$ ordnen. Es lernt sich selbst in diesen Welten zu kalibrieren. Das Potential in Denken, Fühlen und Handeln wird im spiel zum Ausdruck gebracht. Im spiel nimmt das Kind an den kulturellen und sozialen Handlungswelten der Erwachsenen teil. Reale Situationen aus der Lebenswelt der Erwachsenen werden "nachgespielt" und kognitiv-emotional verarbeitet. Auf diese Weise schaffen sich die Kinder im Spielen eine Art "fiktive" Welt, in der sie "so tun als ob", um sich die Erwachsenenwelt näher zu bringen. Somit haben sie die Gelegenheit die Dinge zu benennen und ihre Gedanken, Gefühle und Wünsche auszudrücken, laut vor sich hinzusprechen oder mit anderen Kindern in Kontakt zu treten und zu kommunizieren.

\section{DEFINITION (TANIM)}

Das Wort "Spiel" kommt von althochdeutsch spil für "Tanzbewegung". Es ist eine Tätigkeitsform, die zum Vergnügen, zur Entspannung, allein aus Freude an ihrer Ausübung, aber auch als Beruf ausgeführt wird (Theaterspiel, Sportspiel, Violinspiel). Es ist eine Beschäftigung, die meistens in Gemeinschaft mit anderen gemacht wird.

Im Duden (2001:713) wird das spiel folgendermaßen definiert: "Tätigkeit, die ohne bewussten Zweck zum Vergnügen, zur Entspannung, aus Freude an ihr selbst und an ihrem Resultat ausgeübt wird; das Spielen: Handlungsweise, die etwas, was Ernst erfordert, leicht nimmt." 
Der niederländische Kulturanthropologe Johan Huizinga definiert das Spiel folgendermaßen. "Spiel ist eine Handlung oder Beschäftigung, die ohne Zwang innerhalb gewisser festgesetzter Grenzen von Zeit und Raum freiwillig nach bestimmten Regeln gemacht werden. Es hat ihr Ziel in sich selber und wird von einem Gefühl der spannung und Freude und einem Bewusstsein des, Andersseins' als das, gewöhnliche Leben'. begleitet" (vgl. Pehlivan 2012:33)

\section{TEORETHISCHE GRUNDLAGE (TEORILER)}

Im Kleinkindalter ist das spiel die Methode der Selbstbildung bzw. des kindgemäßen Lernens. Dies haben schon "klassische" Pädagogen, Philosophen und Psychologen wie John Locke, Friedrich Schiller, JeanJacques Rousseau, Friedrich Fröbel, Sigmund Freud, Maria Montessori, Jean Piaget, Lew Wygotski und Arnold Gehlen erkannt, und dies wird durch aktuelle Forschungsergebnisse bestätigt. Rodari (vgl. Knauf 2009:25) schreibt: "Dass das spiel eine schöpferische Aufarbeitung ist. Es ist ein Prozess, durch den das Kind die Gegebenheiten der Erfahrung miteinander verbindet, um eine neue Realität zu konstruieren. Mit den Dingen spielen bedeutet sie besser kennen lernen..."

Partecke (2006:49) schreibt, dass das spielen ein so facettenreiches Geschehen ist, dass sich Dichter und Denker, Psychologen und Pädagogen seit vielen Jahrhunderten mit dieser besonderen Form der Aktivität im Leben des Menschen beschäftigen. So hat beispielsweise Schiller schon im Jahre 1795 geschrieben, das der Mensch nur da ganz Mensch sei, wo er spiele. Nur im Spiel ist das Kind in der Lage, Ganzheitlichkeit im Erleben und Handeln hervorzubringen.

\subsection{Drei Klassische Psychologische Theorien (Üç Klasik Psikolojik Teori)}

Im Folgenden werden auf die Meinungen der drei bedeutenden Psychologen eingegangen. Alle drei Autoren kommen bei ihrer Deutung des Spiels zu einer gemeinsamen Erklärung.

\subsubsection{Freud (Wunscherfüllung und Katharsis)} (İsteklerin Gerçekleştirilmesi ve Korkulardan Kaçış)

Er selbst hat keine eigene Theorie des spiels entwickelt. Nach Freud hat das Spiel eine Wunscherfüllende Funktion. Im Spiel entfliehen die Kinder den Zwängen der Realität und leben tabuisierte Impulse und aggressive Bedürfnisse aus. Das Kind kann sein spiel nach seiner Lust gestallten und braucht die Realität nicht in acht zu nehmen. Die Katharsis- Hypothese, im Zusammenhang mit Wunscherfüllung spielt für Freud eine sehr wichtige Rolle. Nach dieser Hypothese wird durch erneutes Ausleben früherer Probleme (unerlaubter Triebwünsche) eine "Reinigung" erfolgt, was das Kind von seinen Ängsten befreit. Um die Problemen zu bewältigen wiederholt das Kind die Handlungen. Durch diese Wiederholung wird das Kind zum "Herrscher der Situation" (Freud, 1920:226. Es fügt der passiven Erfahrung auch ein aktives Gegenstück hinzu. (Vgl. Özdoğan 2009:124)

\subsubsection{Wygotski: (Realisation Unrealisierbarer Wünsche) (Gerçekleşmeyecek İsteklerin Gerçekleştirilmesi)}

Nach Wygotski entwickelt das Kind im Spiel "unrealistische" Wünsche. Es wird im Spiel groß, stark und kann die Tätigkeiten der Erwachsenen ausführen. Diese Wünsche sind in der Realität nicht erfüllbar. Die Kinder sind ungeduldig und wollen nicht warten bis sie Erwachsen werden um ihre Ziele zu verwirklichen. Das Kind ist im Gegensatz zum Erwachsenen nicht in der Lage, seine Bedürfnisse 
aufzuschieben. In diesem Fall ist das Spiel die Lösung: Die Wünsche des Kindes werden in der Spielrealität illusionär verwirklicht. Auf die Frage "Weshalb spielt das Kind?" ist seine Antwort folgendermaßen: "Das Spiel kann als eingebildete, illusionäre Realisation unrealisierbarer Wünsche gedeutet werden"(vgl. Wygotski 1933:443). Die Wünsche, die das Kind im spiel hat sind nicht seine konkreten Einzelwünsche, sondern verallgemeinerte Affekte bzw. Wünsche. Das Kind will groß und stark sein deshalb lebt es diesen Wunsch in mannigfaltiger Weise (vgl. Pehlivan 2012:39-41).

\subsubsection{Piaget (Assimilation als Gegenwehr) (Karşı Savunma Olarak Asimilasyon)}

Die Ansichten und Beschreibungen von Piaget (1969) über das Spiel sind weit bekannter als die beiden anderen Autoren. Das spiel ist eine Art Assimilation, d.h. kognitive Aktivitäten, die die Umwelt einseitig an die Schemata des Kindes anpassen. Nach Piaget handelt es sich spätestens ab dem Symbolspiel, bei denen die Gegenstände umdeutet und Fiktionen aufbaut werden, um eine Gegenreaktion gegen den Sozialisationsdruck und dem Druck der allgemeinen Wirklichkeit. Durch das Spielhandeln währt sich das Kind gegen die reale Welt. Das Spiel, das die Welt des Kindes ist hat die Funktion, "diese Welt gegen die erzwungenen Akkommodation an eine allgemeine Wirklichkeit zu verteidigen" (vgl. Pehlivan 2012:36-39). Nach diesen drei Entwicklungspsychologen übernimmt das spiel Aufgaben der Lebensbewältigung zu einem Zeitpunkt, weil andere Techniken und Möglichkeiten noch nicht vorhanden sind.

\section{KORPUS (BÜTÜNCE)}

Wie Onur (2012:154) auch in seinem Buch schreibt, werden die Kinder zurzeit von den Eltern, die Tagsüber arbeiten wegen Besorgnisse um Erfolg in der Schule und später im Beruf zu leisten in den Häusern eingesperrt. Auch die spielplätze sind sehr gering. Somit können die Kinder nur in der Schule in den Pausen Draußen mit anderen Kindern zusammen spielen.

Um den Korpus zu bilden wurden deswegen die spiele der Schüler und Schülerinnen aus drei verschiedenen Grundschulen der Klasse 1-5 (in Konya Akşehir) in der Pause auf Kamera aufgenommen. Nachher wurden die Rollenspiele und die Abzählreime, die mit Händeklatschen und Körperbewegungen vorgespielt worden sind, ausgewählt. Die Zeilen (Verse) der 14 spiele sind unten aufgeschrieben.

- İsveç, Norveç, Danimarka, Belçika, Belçika, Hollanda. Türkiye'nin başkenti Ankara. Ankara Meslek lisesi, eteğimin pilisi. Saçlarımın jölesi, tırnağımın ojesi, erkekler çöp tenekesi, kızlar altın kesesi. Bizim evin arkası, dondurma fabrikası, dondurmalar buz gibi, erkekler karpuz gibi.

- Zeytin kara ben kara, zeytine vermem on lira. İi gelin yan yana, ortasında kaynana. Kaynanayı ne yapmalı? Kaynar kazana atmalı. Yandım gelin dedikçe, altına odun atmalı. Karpuz kestim kan çıktı, içinden yılan çıktı. Benim sevdiğim oğlan asker kaçağı çıktı.

- Yıldızların altında. Herkes bunun farkında. Ben bir oğlan sevmiştim. 13-14 yaşında. Bisiklete binerdik. Yarı yolda inerdik. Ooo annem, babam sorarsa teker patladı derdik. Babam tekere bakar. Yalan olduğunu anlar. Bana bir tokat atar. Aaa eşek şakası yapar. Bak demir kapı açıldı. Bütün kızlar saçıldı. Bunu gören erkekler. Aaa keçileri kaçırdı.

- İsveç, Norveç, Danimarka, Belçika, Belçika, Hollanda. Türkiye'nin başkenti Ankara. Ankara Meslek lisesi. Eteğimin 
pilisi, saçlarımın jölesi, tırnağımın ojesi. Erkekler çöp tenekesi, kızlar altın kesesi. Annem, babam Başbakan. Var mı bana yan bakan? Ali bana yan baktı. 500 hapiste yattı. Beş, beş, beş numara. On, on, on numara. Gir çuvala. Salla salla vur duvara.

- O piti piti karamela sepeti. Terazi lastik jimnastik. Biz size geldik bitlendik. Hamama gittik temizlendik.

- Köylü kızı çamaşır yıkar. Üzeri ıslanmış. Döne döne ağlar. Cıs takta cıs tak, cıs takta cıs tak. Köylü kızı saçını tarar. Tarağı da düşmüş. Döne döne ağlar. Cıs takta cıs tak, cıs takta cıs tak. Köylü kızı inek sağar. İnek de tepmiş. Döne döne ağlar. Cıs takta cıs tak, cıs takta cıs tak.

- Sarıçiçeğim. Ben öleceğim. Cuma akşamı, kan vereceğim. Örtün üstümü, sinek konmasın, beni görenler, korkup kaçmasın. İki iki dört, dört dört sekiz, kımıldayan keriz.

- Tom ve Jerry. Dispanseri. Verem do, do, do. Verem si, si, si. Verem do. Verem si. Ooo Pepsi, ooo Pepsi. Eteğimin pilisi, saçımın Jölesi, tırnağımın ojesi. Ay çok mersi. Ben seni saat 10 da köşe başı, Çin lokantasında bekliyorum. Eğer gelmezsen küsüyorum. Nişanını bozuyorum. Mektubunu kesiyorum. Çiçeğini eziyorum. Ama ben seni çok seviyorum.

- Üşüdüm, üşüdüm, daldan elma düşürdüm. Elmamı yediler, bana cüce dediler, cücelikten çıktım. On deve buldum. Birisine bindim. Teyzeme gittim. Teyzem pilav pişirmiş. İçine kaşık düşürmüş. Bu kaşığı ne yapmalı? Minareden atmalı. Minarede bir kuş var. Kanadında gümüş var. Eniştemin cebinde, türlü türlü yemiş var.

- Ooo Kola, Pepsi, Kola. Amerika, Avrupa, Hollanda. İstanbul gelsin bu tarafa. Darıldın mı cicim bana hiç bakmıyorsun bu yana, esmerim güzelim, ben yanıyorum.

- Kapıdan girdim içeri. Barbie güzeli, Sindy, Sindy, Sindy güzeli. Kim bu dünyanın en güzeli?

- Ebe ebe nerede? Su doldurur derede. Dere boyu çalılık. Nerede olur balık? Şu ebe de ne alık. Oltamı attım. Balığımı tuttum. Balık suya dalamaz. Ebe seni bulamaz. 1-2-3-4-5-6-7. Bunu sana kim dedi? Diyen dedi on yedi. Yağlı böreği kim yedi?

- Can Can çikolata. Hani bize çikolata? Limonata bitti. Hanım kız gitti. Nereye gitti? İstanbul'a gitti. İstanbul'da ne yapacak? Terlik pabuç alacak. Terlik pabucu ne yapacak? Düğünlerde şıngır mingır oynayacak.

- O piti piti karamela sepeti terazi lastik jimnastik. Biz size geldik bitlendik. Dik dik dik. Hamama gittik temizlendik. Kırmızı iplik. Dolapta pekmez yala yala bitmez. Ayşecik cik cik cik. Fatmacık. Cık, cık, cık. Sen bu oyundan çık.

\section{BEWERTUNGSVERSUCHE AUS VERSCHIEDENEN SICHTEN (FARKLI AÇILARDAN DEĞERLENDİRME ÇALIŞMASI) \\ 6.1. Bewertung aus Motorischer Sicht (Motor Gelişimi Açısından Değerlendirme)}

Da das Kind im Unterricht sitzt und sich nicht bewegen kann, kann das Kind seinen natürlichen Bewegungsdrang nur in der Pause ausleben. In den Spielen (1-14) werden durch ständig rhythmisches Händeklatschen Koordinationsfähigkeit, Geschicklichkeit, Kraft und Kondition der Kinder gefördert. Das Kind konzentriert sich im spiel auf die rhythmische Klatschtätigkeit mit dem Partner. 


\subsection{Bewertung aus Kognitiver Sicht \\ (Bilişsel Açıdan Değerlendirme)}

Im Spiel erhält das Kind neue Informationen über seine Umwelt die es speichert und ansammelt.

- Informationen: In der türkischen Gesellschaft wird den Jungen mehr Wert gegeben als den Mädchen. Als Gegenreaktion werden die Jungen von den Mädchen minderwertig angesehen: Jungen sind wie Melonen (1, 4).

- Pflege: Die Faltenröcke sind gebügelt, die Haare sind gestylt, auf den Nägeln sollen Nagellack sein, die Läuse wird man im türkischen Bad los und wird sauber, Wäsche waschen, Haare kämmen, Schönheit(1, 4, 5, 6, 8, 10, 14).

- Der Streit zwischen Schwiegermutter und Schwiegertochter: Die Schwiegermutter sollte man im Topf kochen (2).

- Jugendliche, dies von der Armeepflicht fliehen, werden in der türkischen Gesellschaft nicht gut angesehen (2).

- Wunsch nach bevorrechtet sein, privilegiert sein: Niemand kann ihr schaden. Ali hat sie schief angesehen. Er musste deswegen in 500 Gefängnissen (sitzen) haften (4).

- Die Tätigkeiten der Mädchen in den Dörfern: Wäsche mit der Hand waschen, Haare kämmen, Kühe melken (6).

- Getränke und Lebensmittel in der türkischen Gesellschaft: Kola, Pepsi, Limonade, Karamell, Trauben Most (pekmez), Yağlı Börek, Fisch, Pilav, schwarze Oliven, Eis, Melone, Apfel, Schokolade $(1,2,8,9,10,12,13,14$,$) .$

- Flirten: Sich irgendwo heimlich (von den Eltern) treffen, Mädchen, die sich mit ihrem Freund treffen, werden von dem Vater geschlagen, mit dem Freund bzw. Mit der Freundin Zeit vertreiben, sich streiten und nicht mehr sprechen, die Verlobung brechen, Blumen vom Freund zertreten, die Briefe zerreißen, sich unter den Sternen treffen, die Eisentür aufmachen und die Mädchen raus lassen $(3,8,10)$.

- Die Schwester der Mutter wird als die Hälfte der Mutter angesehen. In schweren (schlechten) Zeiten geht man zur Schwester. (9).

- Die europäische Länder sind wichtig. Deutschland Dänemark, Holland, Norwegen usw. (1,4,10). Auch für Amerika interessieren sich die Kinder sehr. (10). Istanbul und Ankara sind wichtige und angesehene städte der Türkei. (1, 4, 10, 13).

- Auf der Hochzeit tanzt man. $(4,13)$.

- Eine Angesehene Schule für die Kinder ist das Berufsgymnasium in Ankara (Ankara Meslek Lisesi). (1, 4).

- Die frontation mit dem Tod. (7).

- Sanitätsstation für Lungenerkrankungen: Lungenerkrankungen gab es früher in der Türkei viel. (8).

\subsection{Bewertung aus Sozialer Sicht (Sosyal Açıdan Değerlendirme)}

Durch das spielen haben die Kinder Kontakt zu den Freunden und Freundinnen. Sie müssen sich auch an die Klatschregeln halten. Die Lieder haben in sich eine Reihenfolge. Die Kinder spielen nur mit Kindern, die sich an die Regel halten. Die Kinder schlüpfen in verschiedene Rollen. (Z.B. Schwiegertochter (2); Erwachsener, der ein Geliebte hat, sich mit seiner Geliebten trifft, sich verlobt $(2,3,8$, 10); geht zum Gymnasium und stylt sich die Haare, trägt Faltenröcke, lackt die Nägel; ist das Kind eines Ministerpräsidenten (privilegierten) (4); die Rolle eines Dorf Mädchens (6); die Rolle 
eines Kranken (7); eines Erwachsenen, der nach İstanbul zum Einkaufen geht (13).)

\subsection{Bewertung aus Psychischer Sicht (Zihinsel Açıdan Değerlendirme)}

Spannungen zwischen Mädchen und Jungen in der türkischen Gesellschaft (1, 4); Spannung zwischen Eltern und ihrer Tochter, die einen Jungen liebt (3); Spannung zwischen sauber und dreckig (mit Läuse) sein (5); Spannung zwischen leben und sterben.

Konflikt zwischen Schwiegertochter und Schwiegermutter (2); Jungen, die vor der Armeepflicht, fliehen soll man nicht lieben, aber das Mädchen liebt ihn (2); Streit mit dem Geliebten (10). Das Selbstvertrauen der Mädchen wird gestärkt durch gepflegt sein und höflich sein. $(8,11)$.

\subsection{Bewertung aus Emotionaler Sicht (Duygusal Açıdan değerlendirme)}

Die Kinder lernen unterschiedliche Gefühle und wie sie mit diesen Gefühlen umgehen müssen: Auf der Hochzeiten tanzen, Tod, Neid gegen Jungen, Verlobung brechen, sich mit dem Geliebten treffen, Haß gegen Schwiegermutter, Schönheitsvorbilder sind Barbie und Sindy, Lieblingsessen und Getränke sind Pepsi, Kola, Limonade, Eis, Karamel, Schokolade usw. (1, 2, 8, 9, 10, 12, 13, 14).

\subsection{Bewertung aus Sprachlicher Sicht (Dilsel Açıdan Değerlendirme)}

Dinge Benennen: Askerkaçă̆ı, Barbiegüzeli.

Die folgenden Gefühle werden Ausgedrückt: - Für Schwiegermutter sollte man kein Mitleid haben. - Die Gefühle der Dorfmädchen sind vorwiegend vom Weinen geprägt. - Mädchen wollen durch Ärgern der Jungen (mit ihnen) in Kontakt treten und kommunizieren (Jungen sind wie Mülleimer, sind wie Melonen, Jungen, die die Mädchen sehen, drehen durch). - Wütend auf dem Liebling, der nicht zum Treffpunkt kommt (deswegen Blumen zertrampeln, Briefe zerreißen, nicht sprechen), der Freund soll sie lieben.

Gedanken und Wünsche ausdrücken: Schwiegermutter sollte man im Topf kochen, bei den Hochzeiten tanzen, hinter ihrem Haus sollte eine Eisfabrik sein, die Tür aus Eisen sollte aufgemacht werden, will nach Istanbul fahren und einkaufen, will verschiedene Länder (Amerika, Belgien, Holland, Deutschland usw.) sehen, will essen und trinken (Kola, Pepsi, Schokolade, Eis usw.), Mutter und Vater sollen Staatspräsident sein, will sich mit dem Liebling treffen, will sich verloben, Haare stylen, Fingernägel lackieren, gebügeltes Faltenrock tragen. Die Ohrfeige vom Vater sollte Spaß sein, die eiserne Tür soll für die Mädchen aufgemacht werden, Mitleidwunsch nach dem Tod, Wunsch nach Süßigkeiten: Kola, Pepsi, Eis, Karamell, Wassermelone usw.

\section{SCHLUSSFOLGERUNG (SONUÇ)}

In diesem Absatz wird kurz darauf eingegangen, was die türkischen Kinder auf dem Schulhof mit ihren spielen uns sagen wollen, was ihre Ängste sind, wogegen sie sind und was sie im realen Leben erwartet.

Von dem obigen Korpus kann man folgendes erschließen:

Ihre Lieblingsgetränke sind Pepsi, Kola und Limonade. Schokolade, Karamell und Eis sind auch bevorzugte Naschmittel von den Kindern. Wie auch aus vielen Zeilen zu ersehen ist, ist der Wunsch der Mädchen nach einem Freund sehr hoch, was kulturell und religiös in unserer Gesellschaft nicht erlaubt ist. Es besteht ein großer Wunsch nach 
Flirten und mit dem Gegengeschlecht Zeit zu vertreiben. Mädchen fürchten immer noch von den Eltern ausgeschimpft und geschlagen zu werden. Deswegen lügen sie, wenn sie sich mit ihrem Freund treffen. Die Mädchen sollten nicht heimlich von den Eltern Flirten. Das Meckern und sogar das Schlagen der Mädchen die mit Jungen flirten, sollte auch eingestellt werden.

Auch ein Verlangen nach "gepflegt sein" ist aus den obigen Zeilen zu ersehen. Die Mädchen wollen keine Schuluniforme sondern gebügelte Faltenröcke tragen. Sie wollen ihre Haare mit Gel stylen und ihre Fingernägel lackieren was immer noch in unseren schulen verboten ist.

Was von den Spielen der Kinder zu ersehen ist und leider auch noch erwähnt werden muss, ist, dass der Wert der Mädchen in der türkischen Gesellschaft minder ist als die Jungen. Der Wunsch der türkischen Mädchen ist, auf der gleichen Ebene wie die Jungen zu sein. Deswegen verachten sie die Jungen auch in ihren spielen und vergleichen die Jungen mit Mülleimer und Wassermelonen.

Es scheint auch so, dass der kulturelle streit, der in der türkischen Gesellschaft zwischen der Schwiegermutter und Schwiegertochter besteht, noch ein paar zehn Jahre dauern wird. Der Streit wird so stark dargestellt, dass ein großes Begehren nach dem Vernichten (durch kochen im Topf) der Schwiegermutter besteht, was auch uns die Ängste der Mädchen darstellt.

Wenn man diese spielwelten der türkischen Kinder in acht nimmt sieht man die Gefahr der Erwachsenenrealität, die unsere Kinder jetzt und auch in der Zukunft im realen Leben erwartet.

Die Gedanken und Wünsche der Kinder in den spielen zeigen uns die Klüfte, die in unserer türkischen Gesellschaft unter der mentalen und sozialen Kultur vorhanden sind. Die Gründe für diese Klüfte sind meiner persönlichen Meinung nach nur Erziehungsmängel. Wenn wir eine bessere und gesündere Gesellschaft gründen wollen, sollten wir dringend über diese mentale- und soziale Kulturklüfte als Erwachsener nachdenken, unsere Gesellschaft und besonders unsere Kinder darüber aufklären.

\section{LITERATURVERZEICHNIS (KAYNAKÇA)}

1. Akandere, M., (2013). Eğitici Okul Oyunları Nobel Akademik Yayıncılık Ankara

2. Bartnitzky, H., Brügelmann H., Hecker, U., Heinzel, Schönknecht, F.G., Hamdan Speck, A., (2009). Frankfurt am Main, Herausgeber: Der Vorstand des Grundschulverbandes e.V.

3. Der Große Duden, (2001). Dudenverlag Mannheim

4. Göncü, Ö., (2012). Okul Öncesi Eğitim kurumlarında Müzikli Dramatizasyon Çalışmalarının incelenmesi: E-Journala of New World Sciences Academy. Volume 7, Number 3, Article Number D0097

5. Knauf, H., (2009). Frühe Kindheit gestalten (Perspektiven zeitgemäßer Elementarbildung) Verlag $W$. Kohlhammer stuttgart

6. Onur, B., (2013). Müze ve Oyun Kültürü, İmge Kitabevi Ankara

7. Özdoğan, B., 2009). Çocuk ve Oyun 5. Baskı Anı Yayıncılık Ankara

8. Partecke, E., (2006). in "Beltz Handwörterbuch für Erzieherinnen und Erzieher" Raim und Pousset (Hrsg.) Beltz Verlag Weinheim und Basel

9. Pehlivan, H., (2012). Oyun ve Öğrenme 3. Baskı, Ankara: Anı Yayıncılık.

10. Schlichtinger, M., (2013). Die Bedeutung des Spiels

11. Stöcklin, M., (2010). Spiel. Sprache des Herzens. Wie wir Kindern eine reiche Kindheit schenken Kösel Verlag München 


\footnotetext{
12. Yücel, A.S. ve Gündoğdu, C., (2012). İlköğretimde ve Ortaöğretimde Geleneksel Çocuk Oyunları Nobel Akademik Yayıncılık Ankara.
} 